\title{
Effects of surface roughness on sea ice freeboard retrieval with an Airborne Ku-Band SAR radar altimeter
}

Hendricks, Stefan; Stenseng, Lars; Helm, Veit; Haas, Christian

Published in:

International Geoscience and Remote Sensing Symposium proceedings

Link to article, DOI:

10.1109/IGARSS.2010.5654350

Publication date:

2010

Document Version

Publisher's PDF, also known as Version of record

Link back to DTU Orbit

Citation (APA):

Hendricks, S., Stenseng, L., Helm, V., \& Haas, C. (2010). Effects of surface roughness on sea ice freeboard retrieval with an Airborne Ku-Band SAR radar altimeter. In International Geoscience and Remote Sensing Symposium proceedings (pp. 3126-3129). IEEE. https://doi.org/10.1109/IGARSS.2010.5654350

\section{General rights}

Copyright and moral rights for the publications made accessible in the public portal are retained by the authors and/or other copyright owners and it is a condition of accessing publications that users recognise and abide by the legal requirements associated with these rights.

- Users may download and print one copy of any publication from the public portal for the purpose of private study or research.

- You may not further distribute the material or use it for any profit-making activity or commercial gain

- You may freely distribute the URL identifying the publication in the public portal 


\title{
EFFECTS OF SURFACE ROUGHNESS ON SEA ICE FREEBOARD RETRIEVAL WITH AN AIRBORNE KU-BAND SAR RADAR ALTIMETER
}

\author{
Stefan Hendricks ${ }^{1}$, Lars Stenseng ${ }^{2}$, Veit Helm ${ }^{1}$, Christian Haas ${ }^{3}$ \\ ${ }^{1}$ Alfred-Wegener Institute for Polar and Marine Research, Bremerhaven, Germany \\ ${ }^{2}$ DTU-Space, Technical University of Denmark, København, Denmark \\ ${ }^{3}$ Earth and Atmosphere Sciences, University of Alberta, Edmonton, Canada
}

\begin{abstract}
Results from two years of the CryoSat Validation Experiment (CryoVEx) over sea ice in the western Arctic Ocean are presented. The estimation of freeboard, the height of sea ice floating above the water level, is one the main goals of the CryoSat-2 mission of the European Space Agency (ESA) in order to investigate sea ice volume changes on an Arctic wide scale. Freeboard retrieval requires precise radar range measurements to the ice surface, therefore we investigate the penetration of the $\mathrm{K}_{u}$-Band radar waves into the overlying snow cover as well as the effects of sub-footprint-scale surface roughness using airborne radar and laser altimeters. We find regional variable penetration of the radar signal at late spring conditions, where the difference of the radar and the reference laser range measurement never agrees with the expected snow thickness. In addition, a rough surface can lead to biases of the airborne validation dataset, since the radar overestimates the amount of open water and thin ice as well the freeboard of heavy ice deformation zones.
\end{abstract}

Index Terms - Sea ice, snow, radar altimetry, synthetic aperture radar

\section{INTRODUCTION}

Remote sensing of sea ice thickness on a basin scale is solely realized with freeboard measurements by satellite altimeter platforms (e.g. [1] and [2]). Freeboard, the height of the sea ice respective snow above the water level, can be estimated by differences of altimeter range measurements over open water and sea ice. Based on the assumption of isostacy and with additional information of snow thickness as well as ice and snow density, freeboard can be converted into sea ice thickness. But since freeboard only represents a small fraction of the total thickness column of floating sea ice, high accuracy of range measurements is required.

The European Space Agencys (ESA) CryoSat-2 mission [3] uses a synthetic aperture and interferometric radar altimeter system. Uncertainties in the CryoSat- 2 range measurements over Arctic sea ice arise from two sources. First, the penetration of the $\mathrm{K}_{u}$-Band radar waves into the snow layer may be depend on region and time of the year, because of variable physical properties of the snow layer. Second, sea ice has a rough surface and is divided into floes of different spatial scales. Especially in ice deformations zones, which hold a significant part of the Arctic sea ice volume, a high freeboard variability has to be expected within the $250 \times 1000 \mathrm{~m}$ footprint of CryoSat-2.

Here, we present results of CryoSat-2 pre-launch validation measurements obtained with an airborne radar and a laser altimeter in key sea ice regions of the Arctic Ocean. The laser measurements serve as a surface reference for the radar data, since laser beams are always reflected at the top snow surface. The penetration of $\mathrm{K}_{u}$-Band radar waves into the snow layer has been the focus of many studies in the Arctic ([4] and [5]) and the Antarctic ([6] and [7]). In this work, we verify earlier findings with large-scale measurements and investigate the additional effect of surface roughness on the freeboard retrieval with airborne radar altimeters in key sea-ice regions of the Arctic Ocean.

\section{DATA AND METHODS}

All data presented here was collected during the ESA CryoSat Validation Experiment (CryoVEx). The key instrumentation consists of the Airborne Synthetic Aperture and Interferometric Radar Altimeter System (ASIRAS) and an across-track scanning laser altimeter mounted on a fixed-wing airplane (see Figure 1). In support for both laser and radar range measurements, two Differential GPS (DGPS) antennas for exact geolocation and an Inertial Navigation System (INS) for aircraft attitude corrections were mounted as well. ASIRAS was constructed as a replica of the CryoSat- 2 altimeter SIRAL scaled to accommodate the airborne environment. The ASIRAS altimeter operates at a center frequency of 13.5 GHz ( $\mathrm{K}_{u}$-Band) and features along-track resolution enhancement by means of the synthetic aperture radar (SAR) technique like its satellite-borne counterpart. The return echo power for each data-point is recorded with a vertical sampling of approximately 0.1 meter in a 24 meter range window. From these echo waveforms, the surface is tracked by a Threshold 


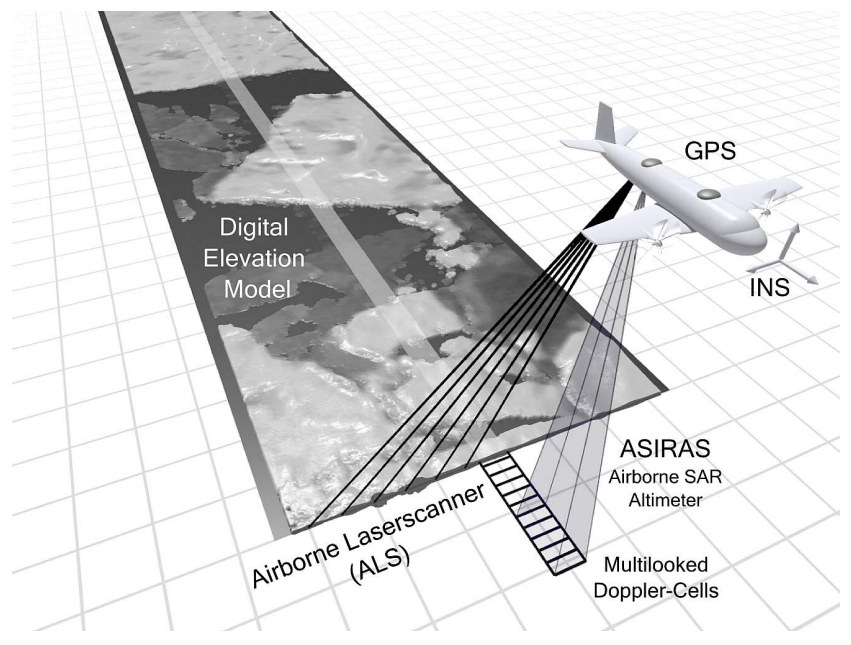

Fig. 1. Instrumentation for the CryoVEx sea ice field activities. Digital elevation models are retrieved by a across-track scanning laser altimeter and an along-track SAR altimeter (ASIRAS) and Two Differential GPS (DGPS) antennas and an Inertial Navigation System (INS)

Spline Retracker Algorithm (TSRA) [8].

The field activities took place in late spring 2006 and 2008 in the Greenland and Lincoln Sea in the western Arctic Ocean. The Greenland Sea with the Fram Strait is the major outflow region for multi-year ice (MYI) of the Arctic Ocean, while the coastline and major ice drift pattern result in thick heavily deformed sea ice in the Lincoln Sea. With the observed reduction of MYI in the Arctic [9] the measurements took place in one of the key regions for sea ice in the Arctic Ocean.

\subsection{Estimation of freeboard}

Several hundred kilometers (2006: 888 km, 2008: 1360 km) of profile data from early May each year were analysed. For all profiles digital elevation models (DEMs) where calculated from both laser and radar instruments. The resolution of the DEMs vary with flight altitude and operation mode for ASIRAS. Typically the along-track resolution of the ASIRAS measurements is $3 \mathrm{~m}$ and $1 \times 1 \mathrm{~m}$ for the laser scanner derived DEM. The calibration and geolocation of both instruments were validated using overpasses of runways and defined features, such as buildings.

To estimate freeboard from the elevation data of both altimeters, frequently occurring patches of open water between sea ice floes were manually detected. An interpolation of the sea surface height profile was then subtracted from the ice/snow surface elevation profile yielding laser- and radar-freeboard. A local sea-surface model for each profile is necessary to correct local variations due to ocean currents and atmospheric pressure changes, not present in a geoid model.
As a last processing step the higher resolution laser DEM was gridded to match the radar footprint, yielding comparable laser- and radar-freeboard with typical 20 laser data points within the footprint of one ASIRAS freeboard estimate.

\section{RESULTS}

The results of the laser- and radar-freeboard are displayed as probability distributions of freeboard partitioned by region and year in Figure 2. All distributions show two distinct maxima, the first one at very low freeboard values $(<0.2 \mathrm{~m})$ and a second around $0.5 \mathrm{~m}$. While the first maximum shows the amount of open water and thin ice in the profile data, the second maximum, or mode, represents the dominant sea ice class, which is typically undeformed sea ice. Higher freeboard values originate from rough, deformed sea ice. One striking feature is the different amount of open water and thin ice measurements, represented by the very different magnitude of the first mode for both sensors. This can be explained by the instrument characteristics, because specular reflections of the oblique laser beams over the very level targets result in very few laser returns, ultimately leading to data drop-outs. For the much wider ASIRAS antenna beam pattern however, these areas of specular reflection dominate the return echo power, even if the open water or thin ice covers only a fraction of the footprint. The result is a statistical underrepresentation of laser freeboard data and an overrepresentation of radar freeboard data of thin ice and open water.

The difference of the second modal position between laserand radar-freeboard can give a first estimate of an apparent penetration of the radar waves into the snow layer. The difference of the modes of laser- and radar-freeboard is 5 - 15 $\mathrm{cm}$ in the Greenland Sea, with a less significant difference in 2008. In opposition, no relevant difference can be observed in the Lincoln Sea at all. The apparent penetration found in the Greenland Sea does not equal the expected snow thickness in this region and time of the year. In addition, it is further reduced if the lower propagation speed of the radar waves in the snow layer is taken into account. Judging from the modes of laser- and radar-freeboard, no penetration at all can be observed in the Lincoln Sea in both years. However, this probabilistic approach cannot completely guarantee that data points which contribute to the individual modes are from the same spots in the ice surface. Hence, a point-to-point comparison is necessary.

\subsection{Influence of Surface Roughness}

The direct comparison of laser- and radar-freeboard datapoints shows a wide-range of differences, resulting from the partially random and erratic freeboard retrieval of blocky deformation zones, which are frequent in both regions and years. As an illustration, the point-to-point difference density between both instruments are plotted in Figure 3 against 

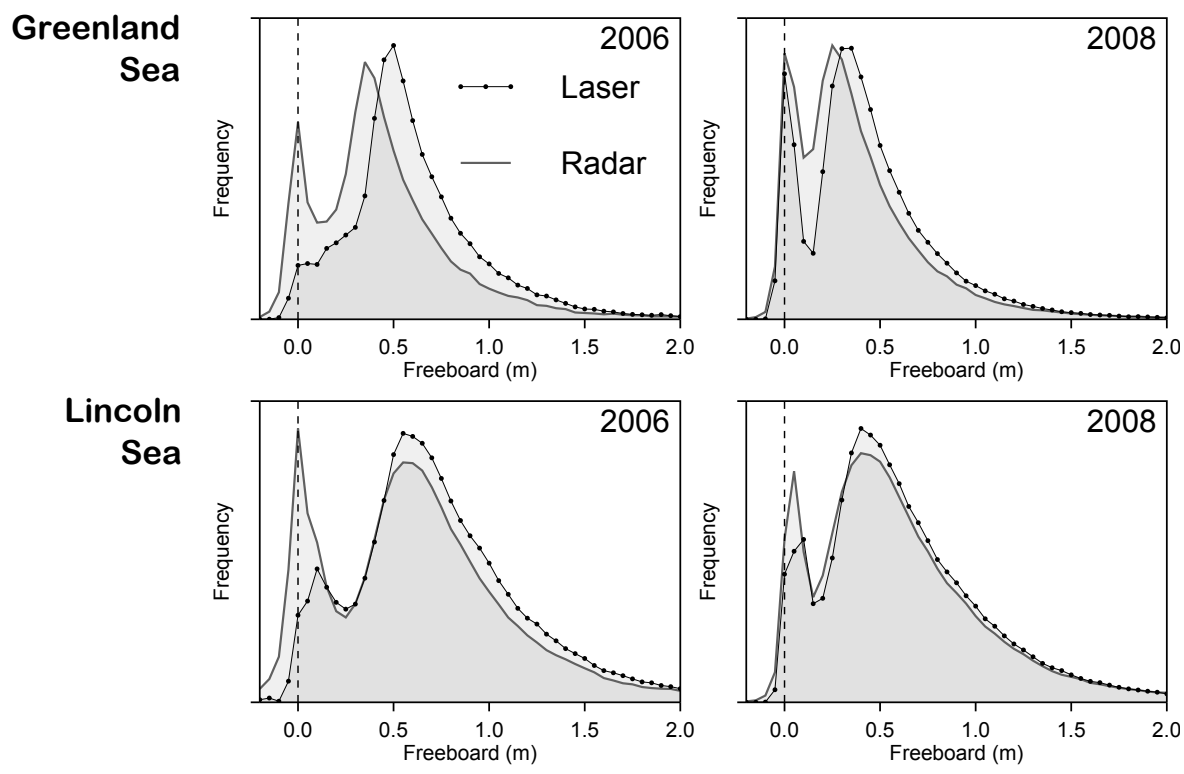

Fig. 2. Distributions of laser- and radar freeboard of the CryoVEx 2006 \& 2008 field campaigns in the Greenland and Lincoln Sea

the reference laser-freeboard. As expected, the variability in the freeboard difference increases with the laser-freeboard, which shows the influence of the rough deformation zones on the uncertainty of the freeboard retrieval. However, distinct clusters reveal the same ice types as represented by the modes in Figure 2. The center of the clusters mostly verify the findings of the apparent penetration obtained by the difference of modal freeboard. Only data from the Greenland Sea in 2006 show a significant positive difference with partial penetration of the radar signal into the snow layer. In the Lincoln Sea data of 2008, the difference density even indicates more negative differences at a laser freeboard of $0.3-1.0$ meter, which means an overestimation of the radar freeboard of this ice class. The overestimation is more pronounced close to the coast, where the ice is more deformed than further off-shore (not shown here).

\section{DISCUSSION AND CONCLUSION}

The results of this study show that under late-spring conditions, $\mathrm{K}_{u}$-Band radar waves show none or only partial penetration into the snow layer of Arctic sea ice. This finding in line with results from case studies over level Antarctic sea ice [7]. In addition, we could show with a large area coverage, that the apparent penetration shows regional variations between the Greenland (partial penetration into the snow) and Lincoln Sea (no penetration). Other remote sensing backscatter datasets like QuikScat-like backscatter maps of the Arctic can help to identify these regional variations and improve the CryoSat-2 sea ice thickness product.

However, the results of the apparent penetration presented here may have limited significance for snow conditions in winter or early spring, when the snow layer is colder and dryer. Validation data is sparse due to the extensive logistical demands and safety constraints for field campaigns in these earlier periods. The first CryoSat-2 post-launch validation campaign in 2011 will therefore take place a month earlier to improve the understanding of radar wave interaction at much colder conditions.

In addition to the investigation of the radar wave penetration, our results also show the importance of surface roughness for airborne validation activities. Airborne data collection is the intermediate step between small-scale In-Situ studies and global-scale satellite measurements. We have demonstrated that the airborne laser- and radar altimeter data can be statistically biased by the presence of small patches of open water as well as heavy ice deformation zones. The incomparable footprints of the airborne and spaceborne measurements prevent a direct projection of these errors onto the satellite data. However, these biases have to be carefully considered for the post-launch validation activities, when a direct comparison of airborne and CryoSat-2 freeboard statistics will be possible.

\section{ACKNOWLEDGMENTS}

The work of Stefan Hendricks and Veit Helm within the German CryoSat Office (www.cryosat.de) was funded by the German Aerospace Center (DLR). The field campaigns were funded and supported by the European Space Agency. We thank Robert Cullen (ESA) for valuable support of the radar data processing. Malcom Davidson and Rene Forsberg are thanked for campaign planning and implementation. 

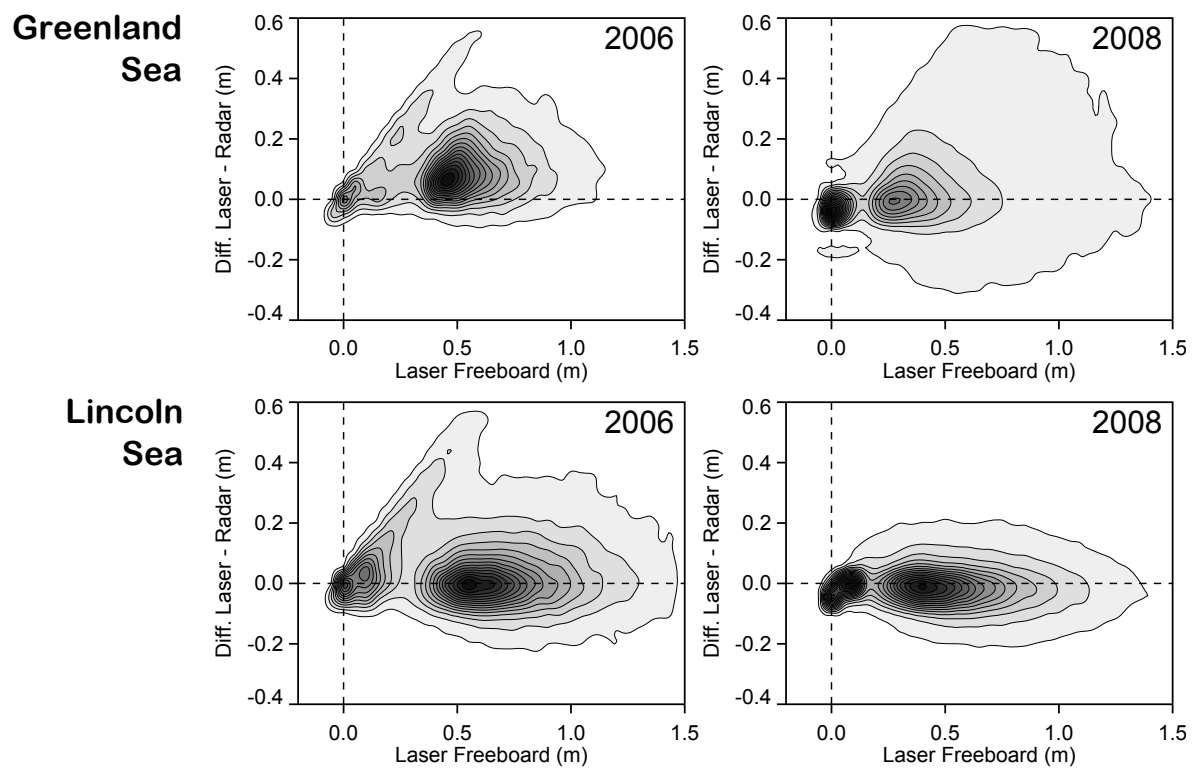

Fig. 3. Density of point-to-point laser- and radar-freeboard differences for the respective laser-freeboard. High freeboard is typically encountered over rough, deformed ice.

\section{REFERENCES}

[1] N. R. Peacock and S. W. Laxon, "Sea surface height determination in the Arctic Ocean from ERS altimetry," $J$. Geophys. Res., vol. 109, pp. 7001-+, July 2004.

[2] R. Kwok and G.F. Cunningham, "ICESat over Arctic sea ice: Estimation of snow depth and ice thickness," J. Geophys. Res., vol. 113, pp. C08010, 2008.

[3] D.J. Wingham, C.R. Francis, S. Baker, C. Bouzinac, D. Brockley, R. Cullen, P. de Chateau-Thierry, S.W. Laxon, U. Mallow, C. Mavrocordatos, L. Phalippou, G. Ratier, L. Rey, F. Rostan, P. Viau, and D.W. Wallis, "CryoSat: A mission to determine the fluctuations in Earths's land and marine ice fields," Adv. Space Res., vol. 37, pp. 841-871, 2006.

[4] K.A. Giles, S.W. Laxon, D.J. Wingham, D.W. Wallis, W.B. Krabill, C.J. Leuschen, D. McAdoo, S.S. Manizade, and R.K. Raney, "Combined airborne laser and radar altimeter measurements over the Fram Strait in May 2002," Remote Sensing of Enviroment, vol. 111, pp. 182-194, 2007.

[5] M. P. Mäkynen and M. T. Hallikainen, "Simulation of ASIRAS Altimeter Echoes for Snow-Covered First-Year Sea Ice," Geoscience and Remote Sensing Letters, IEEE, vol. 6, no. 3, pp. 486-490, 2009.

[6] C. J. Leuschen, R. N. Swift, J. C. Comiso, R. K. Raney, R. D. Chapman, W. B. Krabill, and J. G. Sonntag, "Combination of laser and radar altimeter height measurements to estimate snow depth during the 2004 Antarctic AMSRE Sea Ice field campaign," J. Geophys. Res., vol. 113, pp. 4-+, Apr. 2008.

[7] R. C. Willatt, K. A. Giles, S. W. Laxon, L. Stone-Drake, and A. P. Worby, "Field investigations of ku-band radar penetration into snow cover on antarctic sea ice," IEEE Transactions on Geoscience and Remote Sensing, vol. 48, no. 1, pp. 365-372, 2010.

[8] E. J. Ferraro and C. T. Swift, "Comparison of retracking algorithms using airborne radar and laser altimeter measurements of the Greenland ice sheet," IEEE Transactions on Geoscience and Remote Sensing, vol. 33, pp. 700-707, May 1995.

[9] S.V. Nghiem, I.G. Rigor, D.K. Perovich, P. ClementeColón, J.W. Weatherly, and G. Neumann, "Rapid reduction of Arctic perennial sea ice," Geophys. Res. Lett., vol. 34, pp. L19504, 2007. 